\title{
Enunciación
}

http://revistas.udistrital.edu.co/ojs/index.php/enunc

DOI: http://dx.doi.org/10.14483/udistrital.jour.enunc.2014.1.a11

AUTOR INVITADO

\section{¿Cuál lugar para la lectura y la biblioteca en la sociedad actual?*}

\author{
Silvia Castrillón ${ }^{1}$ \\ Para citar este artículo: Para citar este artículo: Castrillón, S. (2014). ¿Cuál lugar para la lectura y la biblioteca en la sociedad \\ actual? Enunciación, 19(1), 145-150. \\ ...pensar em direitos humanos tem um pressuposto: reconhocer que aquilo que consideramos \\ indispensável para nós é tambén indispensável para o próximo \\ Antonio Candido \\ El derecho a la literatura
}

Para comenzar quisiera hacer dos planteamientos que creo deberían ser telón de fondo de lo que diré a continuación: el primero, que la cultura escrita es un bien público y es medio para la construcción individual y colectiva de lo público y el segundo, que la biblioteca, en tanto espacio social complejo sostenido por una red de relaciones, es también un bien y un espacio para la construcción de lo público.

Por otra parte, antes de afirmar si las bibliotecas contribuyen o no a acortar distancias entre pobres y ricos, entre privilegiados y excluidos, creo que es preciso hacernos algunas preguntas acerca del lugar que la lectura tiene en nuestras sociedades.

De manera reciente, a partir del momento en que la sociedad reconoce como inaceptable que un gran número de personas esté excluido de los bienes considerados fundamentales, se han empezado a descubrir en nuestros países a las bibliotecas como aliadas de la lucha contra la exclusión.

Si se reconoce que la función más importante de la biblioteca sería la de facilitar el acceso a la cultura escrita, garantizar la lectura como derecho, es preciso plantear primero algunas reflexiones acerca del valor que la sociedad otorga a la lectura, a la escritura y al libro, y si estos forman parte de los bienes considerados esenciales a la existencia humana.

¿Cómo imagina la sociedad la lectura? ¿Qué sentido tiene para ella esta práctica? ¿Cómo la ejerce y con qué propósitos lo hace?

Hace poco más de diez años, en un encuentro iberoamericano organizado en Madrid por la Fundación Germán Sánchez Ruipérez, dos personas se referían justamente a este sentido que la sociedad otorga a la lectura, una de ellas, el sociólogo español Enrique Gil Calvo, decía que a comienzos del siglo XX la lectura se consideraba como "destino", dado que tanto individual como colectivamente representaba una herramienta de construcción de futuro, y que esa vieja idea de lectura había sido reemplazada a finales

Conferencia presentada en la Festa Literária Internacional de Paraty, FLIP, Brasil, 5 de agosto de 2012, con algunos ajustes realizados en 2014.

1 Bibliotecóloga de la Universidad de Antioquia; escritora, traductora y editora; ha liderado en Colombia la creación de diferentes entidades de fomento de la lectura: Fundalectura, Asolectura y la Asociación Colombiana para el Libro Infantil y Juvenil, ACLIJ. Ha participado en los consejos directivos de la Asociación Internacional de Lectura, IRA y la Organización Mundial para el Libro Juvenil, IBBY; ha sido asesora de Unesco, OEA, OEI, SECAB y Cerlalc; es autora de libros como El derecho a leer y a escribir (Conaculta, 2011). Correo electrónico: silvia.castrillon@gmail.com 
del siglo por una "lectura como cesantía", es decir para los momentos de desocupación, una lectura más consumista y ociosa (Gil Calvo, S.f., pp.13-25).

Por su parte, la escritora argentina Graciela Montes, la persona que a mi juicio ha cuestionado desde hace más tiempo y con mayor belleza y profundidad muchos lugares comunes creados alrededor de la lectura, se planteaba si

en lugar de acumular argumentos (y sofismas a veces) en torno al concepto [de lectura], podemos empezar a preguntarnos si hay un sitio significativo [...para ella]. Sin este sitio no hay legitimidad que alcance. [...] Da la sensación de que nuestro tiempo [...] ha perdido su confianza en la lectura, no está muy seguro de para qué sirve y avergonzado de haber dejado algo tradicionalmente tan valioso, de a ratos compone elegías sobre ella, y de a ratos la disfraza y la hace bailar como a un monito. (Montes, 1998, p.86)

Por mi parte, creo que la mayoría de los acontecimientos, discursos, eventos, son fruto de esa formulación de deseos de muchos de los que consideramos que la lectura debería seguir teniendo un cierto lugar en la vida de las personas, aunque no todos imaginemos que ese lugar sea el mismo, ni sea igual para todos.

Digamos para comenzar que la lectura tiene un lugar en nuestra época. Se habla de ella, es tema de eventos como este y de preocupación por parte de autoridades de educación y cultura, así como de padres y maestros. Se producen libros, se construyen bibliotecas, se promueve la lectura mediante todo tipo de actividades y estrategias. Se intenta atrapar lectores de mil maneras. No se puede dudar, la lectura tiene un lugar.

¿Pero qué lugar? ¿Qué sentido tiene y con qué propósitos se dedican tantos esfuerzos en su promoción? Me inclino a pensar que ya la lectura no tiene, como lo afirmaba Gil Calvo, "el monopolio de la construcción de la realidad" y que deja de ser "criterio de estratificación social". Es decir, ya no sirve para saber en qué hay que creer, ni para indagar sobre el mundo y la realidad y tampoco nos diferencia entre cultos e incultos, entre informados e ignorantes.

Puede ser que la incertidumbre que tenemos sobre la lectura se origine en un modelo de sociedad capitalista, Ilamado ahora economía social de mercado, que la considera poco rentable en términos de productividad y por ello no se privilegie ya la lectura sino como forma de acceso a la información y se valoricen solo las lecturas científicas y técnicas, en el entendido de que podrían ser las únicas con una productividad o de un bien en su condición de mercancía, también con una utilidad concreta para ciertos sectores.

De todas maneras, ya se trate solamente de la lectura con fines utilitarios inmediatos o de la Ilamada lectura recreativa, no podemos despojarnos de la sensación de que es importante y de que algo importante estamos dejando de hacer y por ello es preciso abrirle espacios, hablar de ella, legislar proponiendo su democratización, hacerla objeto de política pública, formular planes nacionales y locales de lectura. Pero al mismo tiempo y, tal vez, debido a la poca claridad acerca de su utilidad, cada vez se deslegitima más, aún al interior de las dos instituciones que por definición tendrían que garantizar, no solo el acceso a ella sino la creación de un sentido para su práctica: la escuela y la biblioteca.

Podríamos decir entonces que la lectura que permite, como dice Graciela Montes: "encontrar una clave, una llave. Interpretar señales, perseguir sentido. Ver el otro lado de las cosas. Hurgar y ahondar. Horadar, explayarse, criticar y tejer, construir un relato" (Montes, p.88), esa lectura, creo yo, es la que ha perdido lugar en la sociedad. 
Y, sin embargo, es justamente esa lectura la que a mi modo de ver podría contribuir de manera más profunda a lograr transformaciones, transformaciones que traigan consigo una sociedad más justa e incluyente pues es la que permitiría a esa mayoría excluida una toma de distancia frente al mundo y frente a realidades creadas y consolidadas, e imaginar y tomar parte activa en la construcción de mundos posibles. Es la lectura que propicia una cierta forma de rebeldía, muy distinta de la lectura que se propone como evasión.

Veamos rápidamente qué pasa con esta lectura en las dos instituciones que tienen a su cargo formar lectores y garantizar el acceso a la cultura escrita: escuela y biblioteca; ¿cuáles son las razones para afirmar que la lectura, por lo menos la lectura a la que me acabo de referir, está perdiendo un lugar en la sociedad y por ende, identidad en esas instituciones?

Por una parte la preocupación actual de la escuela, en términos institucionales, dista mucho de una lectura que se plantee como búsqueda de sentido. La escuela responde a la presión de la sociedad que le pide que forme personas competentes laboralmente y ciudadanos conformes con el orden establecido.

El modelo educativo actual exige un lector acorde con estos principios. Nada que lo distraiga de esas preocupaciones es bienvenido a menos que justamente se requiera ofrecer pausas que permitan retomar el aliento para continuar. Su propuesta es formar las competencias básicas comunicacionales: enseñar a decodificar y comprender un texto escrito — privilegiadamente un texto informativo o llamado científicoy como compensación al esfuerzo que ello implica, ofrecer el placer de leer mediante la lectura recreativa con lo cual se supone se forma el mal Ilamado hábito.

Y en cuanto a la biblioteca pública, parto de la experiencia de mi país que tiene larga trayectoria en esta materia, bibliotecas que se han constituido en ejemplo para países vecinos y que han sido objeto de importantes premios internacionales.

En Colombia se ha venido trabajando desde hace varias décadas en la construcción de bibliotecas públicas, especialmente en las ciudades de Medellín y Bogotá en donde estas son modelo arquitectónico y de organización bibliotecaria.

Sin embargo, pienso que por las razones expuestas arriba, el tema de la lectura, que debería ser central si tenemos en cuenta que la biblioteca pública es posiblemente la única institución con que cuenta la sociedad con funciones asociadas a garantizar a la población no escolarizada el derecho a la cultura escrita y el derecho a la literatura, la lectura, insisto, no tiene un lugar central en estas bibliotecas, ni es materia de reflexión por quienes planifican sus acciones.

Veamos en qué se ocupa la biblioteca pública por lo general en nuestros países:

A mi modo de ver las dos actividades centrales son, por una parte el apoyo a la escuela y por otra, el acceso a las nuevas tecnologías, especialmente a Internet. También se hace cargo de otras manifestaciones del arte y la cultura como la música y el cine.

\section{EL APOYO A LA ESCUELA}

A falta de bibliotecas escolares en casi todo el territorio nacional, la educación ha abandonado en manos de la biblioteca pública una parte esencial del proceso de alfabetización, entendida esta en su sentido más amplio, es decir no solamente como la enseñanza del alfabeto, sino, especialmente, como la que permite una verdadera apropiación del lenguaje escrito.

Con la sustitución de la biblioteca escolar por la pública, la práctica de la lectura por parte de los estudiantes se convierte en ejercicio sin sentido. Las bibliotecas públicas por fuera de las escuelas, visitadas solo por alumnos y casi nunca por maestros, divorciadas de los proyectos educativos, no pueden cumplir con el 
propósito de que niños y jóvenes descubran el valor del texto escrito, especialmente de la literatura y la importancia que esta puede tener para sus vidas.

\section{LAS NUEVAS TECNOLOGÍAS}

La biblioteca pública, acosada por el afán que tiene la sociedad de no perder el tren del desarrollo y de no parecer anticuada, está empeñada en lo que se ha venido en Ilamar la alfabetización digital, cibernética, computacional o informacional $¿$ Está pensando la biblioteca que el tiempo de la lectura y la escritura de la palabra, el tiempo de los libros, está superado? Así lo afirman quienes dicen que en la escuela la biblioteca escolar debe ser desplazada por el aula informática, o cuando un alcalde de un municipio que carece de acceso a Internet dice: 'en este pueblo lo que necesitamos es una biblioteca virtual'.

La preocupación por la alfabetización informacional puede responder a una angustia por llenar los vacíos de una educación, cuyo principal propósito en la actualidad es la formación para las exigencias del mercado laboral.

Carlos Fuentes decía en una conferencia presentada en Bogotá hace unos años que: "pensar que la recepción masiva de información e imágenes en la era electrónica puede suplir los valores de la lengua, es exponerse a una progresiva disminución de las facultades de pensar, criticar e imaginar (Fuentes, 1999, pp.51-64)."

\section{LA PROMOCIÓN DE LECTURA}

La biblioteca se ocupa, por supuesto, de la promoción de la lectura.

Pero, ¿con qué sentido lo hace?, ¿qué entiende ella por lectura? y ¿qué entiende la biblioteca por promoción?

Siendo una acción de carácter al mismo tiempo político-social y pedagógico-cultural, la promoción de la lectura no debe ser confundida con la propaganda convencional — cuando se pretende, por intereses comerciales, inculcar en el otro el deseo y la sensación de necesidad de consumir algo— ni con la beneficencia o la solidaridad — en cuanto busca minimizar sufrimientos y carencias - ni con el proselitismo religioso ni político — cuando se busca la adhesión de la persona a una creencia (y a sus hábitos y valores) o a un partido—. (Britto, S.f.)

Las anteriores afirmaciones que el profesor brasileño Percival Leme Britto presenta en un documento que está sirviendo de base para el trabajo de conjunto de organizaciones brasileñas, nos ayudan a reflexionar acerca de las intenciones de los programas de promoción de lectura que se realizan en las bibliotecas públicas actualmente.

La biblioteca pública no desea parecerse a la escuela y por ello invierte el tiempo que ella le deja en tratar de demostrar que la lectura es agradable, mediante actividades denominadas lúdicas, término que hace unas décadas tuvo en la educación una dimensión liberadora y que ahora ha sido capitalizado por el mercado de las industrias del entretenimiento y tiene la intención de despojar a la lectura de su carácter de herramienta del pensamiento y de la reflexión, tratando de hacerla fácil con el objeto de estimular su consumo sin límite.

Y así, la biblioteca - tanto la pública como la escolar - convierte la lectura en un juego de recreacionistas que niega su invitación a la reflexión y al diálogo interior, al conocimiento del mundo y de sí mismo. Acaba con la intimidad, con el silencio creador y con su invitación al cuestionamiento. Niega, como dice Bartolomeu Campos de Queirós, la fuerza que la palabra tiene para poner orden en el caos, para 
"transformar el desorden en belleza y movimiento", pues con estas actividades la palabra desaparece para convertirse en ruido.

Además, la animación a la lectura se ha convertido en el sucedáneo de la calidad del libro. Cualquier libro, no importa su calidad, puede ser valorizado gracias a la promoción que de él se hace en bibliotecas.

Sin embargo, no quisiera que lo anterior se entienda como una crítica generalizada a las bibliotecas, tanto públicas como escolares. Las primeras responden a una presión de la sociedad y son víctimas del cambio de sentido que la sociedad da a la lectura y las segundas a esta misma presión pero que en este caso se ejerce sobre la escuela.

A partir de este momento quiero destacar lo que a mi juicio también se hace en muchas bibliotecas y especialmente lo hacen muchos bibliotecarios que participan ampliamente de cuestionamientos como el que hago ahora y están convencidos de la necesidad de transformar estas situaciones y de llenar con otro contenido la acción, tanto de las bibliotecas públicas como de las escolares.

Desde hace algunos años se han venido creando espacios para una reflexión acerca de la lectura y la escritura y su promoción. Qué significa leer, por qué leer, por qué promover la lectura, son cuestiones centrales que se debaten en ellos con la ayuda de materiales teóricos, que se leen y se discuten simultáneamente con la literatura y con la presencia de personas que nos visitan y que nos han acompañado en esta reflexión, como Percival Leme Britto, Cecilia Bajour, María Teresa Andruetto, Michèle Petit, Jorge Larrosa, entre otros; quienes también han cuestionado las campañas y programas tradicionales de promoción de la lectura.

A partir de estos grupos de lectura y reflexión se han venido configurando programas de lectura, dentro de las bibliotecas y fuera de ellas, que tienen las siguientes características:

- Ponen la lectura y la escritura al servicio de los seres humanos —niños, jóvenes y adultos—y no al contrario, como a veces sucede.

- Realizan prácticas socializadas de la lectura, en donde los participantes actúan como sujetos activos de un proceso que les permite descubrir, por una parte, sus potencialidades como lectores y escritores, condición necesaria para acceder a la cultura escrita, y por otra, que la lectura les concierne, los convoca y que necesitan de ella, pues lo que observamos es que la mayoría de las personas se sienten rechazadas por la lectura.

- Propone - como plantea Paulo Freire-que las personas que participan en ellos amplíen sus posibilidades de una lectura del mundo autónoma, la cual es menos posible sin la lectura de la palabra.

- Parten del supuesto de que solo con lectura, escritura, reflexión y pensamiento es posible fomentar la lectura, la escritura, la reflexión y el pensamiento. Y que la mejor manera de hacerlo es en grupos.

- Trabajan con todo tipo de poblaciones, especialmente con las que se encuentran en situaciones críticas de marginación, violencia y desplazamiento a causa de la guerra y la pobreza.

- Privilegian la lectura de la literatura frente a otro tipo de textos escritos, sin desvalorizar, ni desalentar otras lecturas. La experiencia literaria y el lenguaje simbólico, sugerido y ambiguo, ofrece diversas posibilidades de comprensión del mundo y de aprehensión de una memoria compartida.

- Parten del principio de que "solo lo mejor es bueno" cuando se trata de ofrecer material de lectura a quienes carecen de ella.

- Crean espacios no autoritarios ni elitistas e invitan a abandonar el esquema asistencialista que ha caracterizado a la mayoría de los programas de fomento de la lectura, en el que unos pocos "que saben lo que los demás necesitan" llevan sus conocimientos a los que "no saben", es decir, a los niños y a los pobres.

- Son programas que no admiten mediciones cuantitativas y están más interesados en saber qué ocurre mediante acompañamientos y observaciones de tipo cualitativo. 
- Por lo general son programas no institucionalizados, realizados por grupos de personas que, si bien algunos trabajan de manera estable en una biblioteca o en una escuela, lo hacen por iniciativa propia y no responden a políticas de la institución.

Por último quiero confesar que dudo mucho de que la solución a la exclusión de la cultura escrita que sufre la mayoría de las personas en nuestros países esté en manos de los maestros, los bibliotecarios o los promotores de la lectura. El problema es más profundo y estructural, es un problema de exclusión social y económica que nace de ambiciones particulares sin límite. Pero tampoco dudo que trabajar por alcanzar una distribución más justa de este bien público que es la escritura, permitiría crear condiciones para que quienes han sido excluidos de ella la conviertan en un instrumento de transformación de sus realidades y de enriquecimiento de sí mismos.

Programas como los que he mencionado pueden ayudar a que algunas personas encuentren en la palabra diversas posibilidades de ser y de tener un lugar en el mundo.

\section{REFERENCIAS}

Britto, L. (S.f.). Para alcançar uma maior e melhor utilização dos livros disponíveis. (Documento inédito).

Fuentes, C. (1999). La educación vitalicia. En Educar tarea de todos (51-64). Bogotá: Fundación Santillana para Iberoamérica, Tercer Mundo.

Gil, E. (1998). El destino lector. En La educación lectora. Encuentro Iberoamericano, V Simposio de Literatura Infantil y Lectura. Madrid: Fundación Germán Sánchez Ruipérez.

Montes, G. (1998). El espacio social de la lectura. En La educación lectora. Encuentro Iberoamericano, V Simposio de Literatura Infantil y Lectura. Madrid. 